\title{
INTEGRATED ENVIRONMENTAL HEALTH RISK ASSESSMENT FRAMEWORK FOR FIREWOOD-INDUCED INDOOR AIR POLLUTION
}

\author{
KHOMOTSO SEMENYA \& FANNIE MACHETE \\ College of Agriculture and Environmental Sciences, University of South Africa, Republic of South Africa
}

\begin{abstract}
This paper presents an integrated environmental health risk assessment framework to assess risks associated with firewood-induced indoor air pollution as an environmental health hazard. The combustion of firewood is associated with the emission of particulate matter, volatile organic and inorganic compounds or gases that are hazardous to human health and the environment. To date, there have been numerous studies and environmental health risk assessment approaches used to measure, monitor and assess environmental health risks associated with firewood-induced and related pollutants. However, many of the aforementioned risk assessment methods followed a narrow approach, thus rendering these studies methodologically one-sided. Consequently, some of these studies drew inferences about the air pollutants and the associated human health risks without identifying the tree species from which such firewood was harvested, as well as the different properties of wood and combustion characteristics including the dynamics of the fireplace where such combustion took place. Some of these studies failed to identify a specific community where particular firewood is used, since different firewood species grow in different areas and are therefore commonly used in communities where the wood is easily found. Most experimental studies on firewood-induced air pollution examined firewood emissions from undefined or unknown wood species. It is for these reasons that the current study aimed to close these methodological gaps by developing a comprehensive integrated environmental health risk assessment framework that considers the firewood user households, common types of wood and conditions of their harvesting, combustion and emissions in the laboratory environment. This study integrated observations, ethnobotanical meta-analysis and experimental study designs into one comprehensive integrated environmental health risk assessment (IEHRA) framework to assess the risks associated with exposure to volatile organic compounds (VOCs) from firewood combustion. The IEHRA was applied in the Senwabarwana villages to assess environmental health risks associated with selected firewood-induced volatile organic compounds. The results were sufficiently comprehensive to identify common ethnobotanical plant species used for firewood in the study area, the frequency of fire making, the conditions in which fire was made and common health problems experienced by firewood user households. Finally, different species of firewood were burnt in a laboratory under simulated kitchen conditions and VOCs were collected for analysis. The results of the VOCs samples differentiated high- and low-risk firewood species.

Keywords: indoor air pollution, environmental health, environmental health risk assessment, exposure assessment, risk characterisation, toxicity assessment, volatile organic compounds.
\end{abstract}

\section{INTRODUCTION}

The scientific credibility of research and its outcomes depend on the strength and rigor of the research methods followed. Environmental health risk assessment (EHRA) is a complex, comprehensive and scientific method of estimating environmental induced health risks associated with probable exposure to potential environmental hazards, as applied in the current study. The above resonates with a range of EHRA definitions from myriad other authors. For example, according to The Institute of Environmental Medicine [1], EHRA is a "multidisciplinary field of environmental health practice that is focused around the methods used to evaluate exposure, predict health risks and outcomes". National Health and Medical Research Council [2] refers to EHRA as a process of estimating the "probability that, within 
a certain timeframe an adverse outcome will occur into a population exposed to chemical pollutants (in air, water, soil or food) under specific conditions". Clearly, a scientifically credible, replicable and methodologically sound framework is required to qualitatively and quantitatively estimate such environmental health risks.

There have been numerous studies that have used different approaches to assess indoor and outdoor induced environmental health risks, including domestic firewood induced air pollution, for example Kapwata et al. [3], Olave et al. [4], Mitchell et al. [5], Parajuli et al. [6], Jung et al. [7] and Joon et al. [8], to name a few. It is evident from that these studies inferred on air pollution induced health risk from a one sided and narrow methodological base. Several methodological gaps from most air pollution induced health risk assessments or EHRA identified and addressed in the current EHRA framework are as follows.

\subsection{Survey as environmental health risk assessment tool}

Survey is one of the most frequently used study designs used in air pollution studies. Survey is a list of questions aimed at extracting specific data from a group of people, [9], [10]. Surveys may be conducted by phone, mail, via the internet, and sometimes face-to-face, Agency for Toxic Substance and Disease Registry [11]. Most employed tools used in survey to collect data are questionnaires and interviews [12]. In air pollution study's authors, Kapwata et al. [3], Parajuli et al. [6] and Rumchev et al. [13] use survey to obtain information about cooking patterns, exposure to potential risk factors, smoking history, occupation and exposure to biomass fuels used in the home for cooking, heating and lighting, details of the house construction, demographic data and an assessment of socioeconomic status. Survey may be structured or semi-structured with open-ended or closed-ended questions, followed by response options. Kothari [10] noted that the use of closed questions leads to ease of processing answers; enhanced comparability of answers; easier to show relationship between variables; easier to make comparisons between variables and easier to make comparisons between respondents. However, Gratt [14] noted that closed-ended questions to be easily analysed statistically but seem to limit the respondent's response. In contrary Open-ended questions lead to a greater variety of responses (able to explore the answer) from participants but are difficult to analyse statistically because the data must be reduced in some manner, [12]. Survey have different modes of administration ranging from self-administration, telephonically or via email. Creswell [12] finds self-administered surveys to be cheaper compared to other modes of administration and having an advantage or reaching a large sample size, cover wide geographical area and excellent for capturing sensitive topics. Other modes of administration have disadvantage of survey being insufficiently completed (questions left unanswered) and in some cases may not be returned to the researcher or be returned late [10]. For example Langbein [15] experienced massive lack of response on questionnaire questions on stove usage, cooking fuels and cooking location and therefore omitted this information in analysis.

\subsection{Observation as environmental health risk assessment tool}

In an observational study, the sample population being studied is measured, or surveyed, as it is [12]. The researcher observes the variables but does not influence the population in any way or attempt to intervene in the study [16]. There is no manipulation by the researcher. Instead, data is simply gathered, and correlations are investigated. Since observational studies do not control any variable, the results can only allow the researcher to claim association, not 
causation. Chakraborty et al. [17] used observation to check ventilation pattern of the houses by considering the total number of windows in kitchen and living room.

\subsection{Experiment as health risk assessment tool}

Survey and observations cannot reflect the mass or concentration of a pollutant that is inhaled by an individual or community or households. The primary challenges with such methodological approach are that surveys and observations are perceptive than factual or concrete. Without experimental measurements, actual air quality problems and the resulting health burden cannot be assessed. Some researchers use experiments to get information on concentrations of pollutants in the smoke formed during indoor fuel combustion or the environment, for example Mitchell et al. [5] and Wright [18]. Dai et al. [19] and Azuma et al. [20] followed experimental methods to assess potential health risks associated with domestic firewood use. Unlike an observational study, an experimental study has the researcher purposely attempting to influence the results (Mouton [16]). The goal is to determine what effect a particular treatment has on the outcome. Researchers take measurements or surveys of the sample population. The researchers then manipulate the sample population in some manner. Since variables are controlled in a designed experiment, the results allow the researcher to claim causation [12]. Other studies (Mitchell et al. [5], Nolte et al. [21], Williams et al. [22] and Plejdrup et al. [23]) used analyses firewood-induced air pollution through experimental methods at a laboratory without prior understanding of the tree species in use or conditions from which such tree species were harvested.

\section{CHALLENGES WITH SURVEY, OBSERVATION AND EXPERIMENT AS TOOL IN ENVIRONMENTAL HEALTH RISK ASSESSMENT}

Some of the studies discussed above do not employ exposure methods to find the linkages between adverse health effects and air pollutants. These studies drew general inferences about the emissions and human health risks without relating the plant species, their use to a specific community. The studies also did not confirm the real use of such wood by a real community. Other studies (Ramos and De Albuquerque [24], Tabuti et al. [25] and Evtyugina et al. [26]) survey method in determining the different firewood species used for domestic fire making. These studies identified tree species through their indigenous ethnobotanical names. This approach was replicated with improvement (adapted) in the current study. The improvements were based on the limitations associated with the verification challenges experiences by Díez and Pérez [27]. This study found that participants mentioned plants that could not be seen by researchers making it impossible to identify such plants. The limitations identified from Venter and Venter [28] and De Winter et al. [29] studies were, namely:

a) The ethnobotanical names from communities are often inconsistent in both writing and pronunciation, thus leading to grammatical errors in the naming of the plant species.

b) South African communities are more ethnically heterogeneous than before; these communities often speak more than one language, leading to a cultural mix. Thus, affecting the ethnobotanical knowledge and use.

c) There is insufficient ethnobotanical literature that clearly differentiates indigenous plants according to various classes and subclasses of species and their characterization features.

\section{ENVIRONMENTAL HEALTH RISK ASSESSMENT THEORIES}

Several studies have applied human health environmental risk assessment (HHRA) to assess risk of chemicals [30]-[35]. The risk assessment method can be direct or indirect. The 
indirect method as applied in these studies [30]-[35] uses data from fixed monitoring stations to estimate exposure to pollutants while direct methods uses biological measurements [36]. Indirect methods have an advantage when the focus is on larger population exposure, which can be done at a shorter time and with minimal resources. Direct assessments are time consuming and expensive, and they are also not feasible for measuring more than one pollutant due to the inconvenience of attaching several samplers close to person's breathing zone. In this study, the environmental health risk assessment is adapted and given a new name Integrated Environmental Health Risk Assessment (IEHRA). It is used to address the concern of potential impact of volatile organic compounds on human health by examining exposures resulting from firewood combustion and the effects of such volatile organic compounds on human health. The framework is based on identifying the emission from firewood combustion in Senwabarwana villages.

The IEHRA framework was therefore applied in Senwabarwana to assess the potential environmental health risks from the volatile organic compounds formed during the combustion of firewood. For the purposes of this study, the Environmental Health Risk Assessment (Machete [30]) was adopted and adapted to a new name - the IEHRA framework (see Fig. 1).

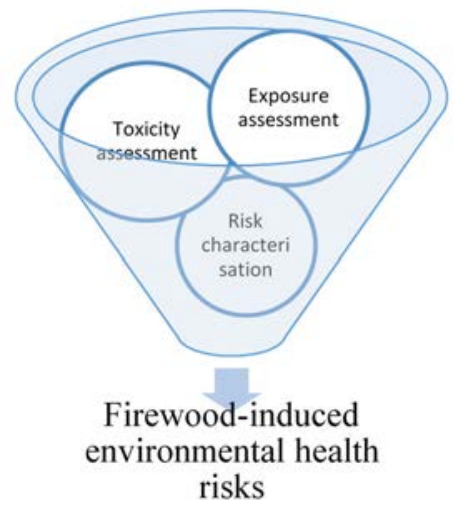

Figure 1: Integrated Environmental Health Risk Assessment framework.

The IEHRA framework was used to assess concerns about the potential impact of VOCs on human health, by examining exposure resulting from firewood combustion and the effects of such VOCs on human health. This framework is based on identifying the emissions from firewood combustion, as measured in Senwabarwana villages. As presented in subsequent sub-sections, the framework encompasses three stages. As shown through Fig. 1, each of the three pillars (components) of the IEHRA framework adopted in this study are discussed in detail below.

\subsection{Toxicity assessment}

To assess toxicity, this stage combines hazard identification and dose response assessment, [31]. There is no single measure of toxicity - different procedures are used, depending on the forms of toxicity (carcinogenic or non-carcinogenic effects). For toxicity assessment, this study integrated four study designs and approaches (survey, observation, ethnobotanical analysis, experimentation). 


\subsubsection{Surveys}

Surveys were conducted by means of structured interviews to assess and analyse the circumstances in which firewood is used in the study area. The survey also laid the groundwork for hazard identification. The current research identified and analysed the different types of trees from which households harvested their firewood. Through descriptive statistical analysis and frequency analysis, priority tree species were identified.

\subsubsection{Observation}

Observation checklist was used to capture qualitative information such as the delivery methods of collected wood, storage area, harvesting tools, kitchen characteristics, building height, floor area, roof type, wall material, stove type, ventilation (number and size of windows, doors and chimney). During this process, the voucher specimens of each plant were photographed, collected, preserved and kept in the Horticulture Centre of the University of South Africa (UNISA), Florida Campus.

\subsubsection{Ethnobotanical analysis}

The names of the plants were given in Sepedi, which is the vernacular language predominantly spoken in Senwabarwana. Books, publications and different websites on vernacular names of plants, were used to assist in identifying the plants by comparing and checking the features. However, the researcher had difficulties in identifying some plants, as they were not appearing in any of the books used. Notwithstanding, plants were arranged in a list with correct common name, botanical name, vernacular name, family name and description of each plant.

\subsubsection{Experimentation}

This stage followed the guidelines set by the Department of Health [37] as well as the manufacturer's guidelines [38], which are based on the World Health Organization (WHO) guidelines. According to Innovative Occupational Hygiene Solutions [39], South Africa does not have legislation and methodologies for monitoring indoor air pollution. Therefore, most companies employ international assessment standards for collecting samples from building surfaces and air, examining the effects of pollutants on human occupants, and determining life-sustaining indoor air quality [40]. Depending on the types of pollutants to be monitored.

\subsubsection{Sample preparation}

The five most commonly used tree species (Red bush willow, Sickle bush, Leadwood, Black monkey thorn) were tested during the experimental phase. According to Creswell [12], many factors affect the performance of a fuel during combustion, including the heat value index, the heat potential, the durability of the embers, its elemental composition, its physical properties (e.g. density, size), its ash residue and the availability of oxygen. All these factors should be taken into consideration when combusting wood fuel. However, this study is not concerned with the combustion properties of firewood, but rather with the emissions. Therefore, the physicochemical properties of the commonly preferred species were not tested. Amongst the participants it was found that the wood was intended for residential heating and cooking and had been air-dried. The wood was cut in equal logs $(1 \mathrm{~kg})$ prior to combustion. According to Inkoom and Crentsil [41], the combustion of $1 \mathrm{~kg}$ of firewood produces harmful levels of emissions. The combustion methods were designed to reflect the Senwabarwana kitchen and stove setup of cooking using a three stone open fire method. A monitor was placed in the cooking area at a level equivalent to the breathing zone of an individual engaged in cooking $(0.5-1 \mathrm{~m}$ above the floor, and $0.5-1 \mathrm{~m}$ from the source). For 
the purposes of this study, it was assumed that factors affecting emissions (such as moisture, ash content, amount of gasifying substances, shape and materials, flue gas outlet dimensions, air supply, stack height, size and shape, natural draft, air supply and mixing, combustion rate, operation habits), from residential wood combustion are constant. This is because residents do not scientifically test for these factors prior to combustion, and this process must reflect the true combustion processes.

\subsubsection{Sampling of pollutants}

Sampling includes the collection of pollutants (analyte) from a known volume of air and the stabilisation of the analyte on the sampling medium [26]. Sampling is usually the most important step in any analytical procedure. Errors committed at this stage cannot be corrected later during the analysis, therefore care was taken during the sampling methods selection process. This study used $1 \mathrm{~L}$ Teflon Tedlar Bags (plastic) to sample a volume of air. These bags are simple to use, affordable, reusable and available in various sizes (normally from $500 \mathrm{~mL}$ to $1.00 \mathrm{~L}$ ). This method enables the measurement of short-term exposures for many substances (sampling duration of a few minutes). A disadvantage of using Tedlar bags is that compounds may not remain stable for more than 24-48 hrs [42]. Some bags are also permeable to certain chemicals, and losses of significant amounts of sample have been observed when they are stored for prolonged periods. To avoid this, samples were taken to the laboratory immediately after sampling. Moreover, Tedlar bags can allow humidity to diffuse when relative humidity levels differ between inside and outside Gawryś et al. [43]. A double-layer Tedlar bag has been designed with a drying agent between the two films, to limit the impact of external humidity on a low-humidity sample Scientific Kit Corporation (SKC) [38].

The bag was connected to a pump, which drew out the volume of air at a flow rate of $5 \mathrm{~mL} / \mathrm{min}$ for $1 \mathrm{~h}$. The bag was filled to less than $80 \%$ of its maximum volume, in accordance with the manufacturer's instructions. The sampling period was $1 \mathrm{~h}$, which is equivalent to the cooking period. For accurate measurements, three replicate tests were performed for each wood species.

\subsubsection{Sample storage}

Samples collected in Tedlar bags were placed in a clean and cool environment (at room temperature) out of direct sunlight to prevent photo degradation. The bag samples were taken to the laboratory with the valve closed, and an identification tag attached. For best results, samples were analysed within $12 \mathrm{hrs}$ of collection, and no later than 24-48 hrs after collection. The samples were sent to the SKC Safety Health and Environment laboratory immediately after sampling. The samples were marked by indicating numbers, the date collected, and the tree species used, to avoid discrepancies.

\subsection{Exposure assessment}

To comprehensively assess potential human exposure to firewood-induced VOCs, the current study used numerous data from two of the four study designs discussed earlier: observation and experimentation. During the observation phase, the researcher assessed the physical structure of the kitchen designs, the floor area (size) of the kitchen in relation to the family size, the number of windows/vents and their ratio to the floor area, and the potential for cross-ventilation, among other things. Lastly, through experimentation, the burning of different wood species within defined standards and the collection of ambient indoor emissions enabled the researcher to simulate the potential emissions that can be inhaled and that can enter the human body via different routes of exposure. 


\subsection{Risk characterisation}

The risk characterisation step combines information on toxicity and exposure, to describe what is likely to happen to those who are exposed. Therefore, risk characterisation, which is the last step in the IEHRA process, summarises all data from the previous two stages/steps (Woolfenden [42], USEPA [44]). In addition, risk characterisation is the stage of IEHRA at which conclusions are drawn, based on the strengths, weight and limitations of the evidence or available data about the environmental hazards resulting from domestic firewood use [11], [31].

\section{RESULTS AND DISCUSSION}

The results are presented according to the three IEHRA stages, namely toxicity assessment, exposure assessment and rich characterisation

\subsection{Toxicity assessment}

Firewood is the dominant fuel type used in the study area. The types of firewood species used as fuel, being preferred for their quality as firewood are Red bush willow (Mohweleri), Sickle bush (Moretshe), Leadwood (Motswiri), Black monkey thorn (Mokgwa), Umbrella thorn (Mushu). Communities have preferences in respect of the type of wood they choose for combustion, as different woods exhibit different burning characteristics [25]. The firewood is collected dry. In cases where wet wood is collected, it is stored in the backyard to allow it to dry before use. It was observed that all the respondents used open-fire three-stone stoves (without chimneys) for cooking. The use of these stoves' releases smoke into the kitchen. Black soot was observed on the walls of some kitchens. This exposes the person responsible for cooking, along with family members and/or neighbours to pollutants in the smoke, which might have affected their health.

During site visits and observation of household kitchens, none of the kitchens was found to show signs of potential presence of firewood sources of BTEX such as glues, paints, furniture wax etc. Thus, except for potential ambient BTEX sources, the above-mentioned domestic BTEX sources were excluded as potential sources of the BTEX found in these kitchens. It was observed that all the respondents used firewood in open-fire three-stone stoves for cooking and this practice has the potential to cause adverse health effects through the inhalation of smoke released from combustion. Through experimentation, toxicological assessment revealed that there are several pollutants released during combustion of firewood species. It was revealed that VOCs such as benzene, toluene, ethylbenzene and xylene are released as pollutants from the combustion of the firewood used as fuel in Senwabarwana. Fig. 2 shows the selected VOCs emitted per firewood species and their concentration. Higher concentrations could be expected in winter months when the area becomes prone to pollution accumulation due to climatic conditions. The results indicate that Mushu had the highest benzene concentration followed by Moretshe, exceeding the detection limit of one micron per $\mathrm{m}^{3}\left(1 \mu \mathrm{g} / \mathrm{m}^{3}\right)$. The lowest benzene concentration was detected in Motswiri, Mokgwa and Mohwiliri.

These measured concentrations are treated as intake rather than dose because it is known how much of the inhaled pollutant is absorbed by the body. The legal limits on emissions of, and exposure to, VOCs vary from country to country and are set by authorities such as the European Union and the United States Occupational Safety and Health Administration (OHSA). At present, there are no official regulations for VOC emissions for South Africa, 


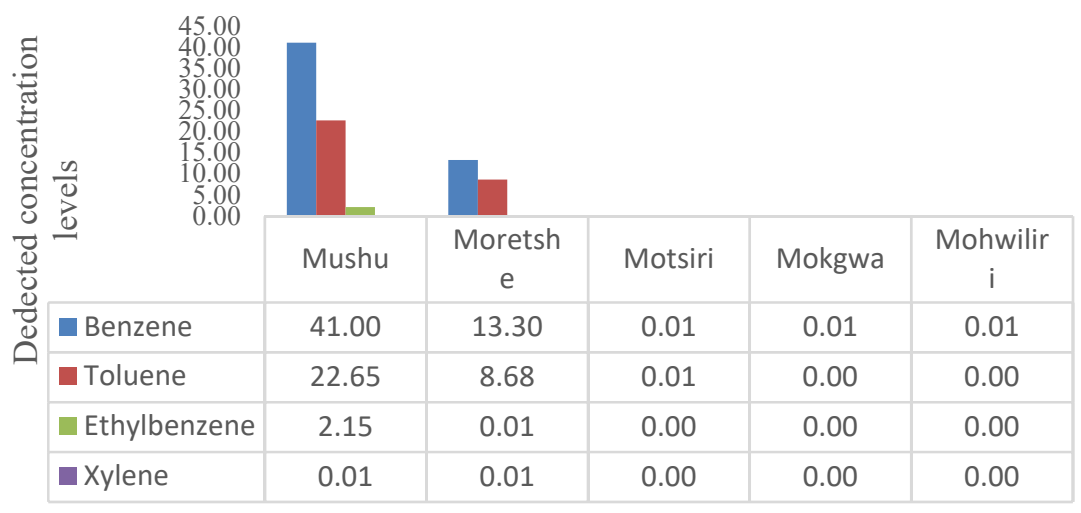

Figure 2: Detected levels of VOCs concentration per selected tree species $\left(\mu \mathrm{g} / \mathrm{m}^{3}\right)$.

apart from benzene for protection of human health and the environment despite VOCs playing an important role in the tropospheric chemistry and potentially causing serious effects on human health. The National Environmental Management: Air Quality Act 2004 (Act No. 39 of 2004) of the Republic of South Africa gives the national ambient air quality standards for pollutants such as sulphur dioxide, nitrogen dioxide, particulate matter, lead, ozone and benzene, but nothing for other VOC, hence international standards are often used (Republic of South Africa, 2004). The legal limits assume that toxic effects will not occur until a threshold dose is exceeded [2], [9].

According to the Agency for Toxic Substance and Disease Registry [11], benzene is a genotoxic carcinogen in humans, and no safe level of exposure can be recommended. It is therefore necessary to reduce indoor exposure levels as far as possible. From parameters published by the Department of Environmental Affairs, the national ambient air quality standard for benzene, per year, is $10 \mu \mathrm{g} / \mathrm{m}^{3}$. The health effects associated with benzene are that it causes cancer and damage to the immune system, as well as neurological problems and possibly reduced fertility.

As noted in Fig. 2, high concentrations of toluene were emitted from Mushu, followed by Moretshe, and low concentrations from Motswiri, and no toluene was detected for Mokgwa and Mohwliri. Exposure to toluene causes headaches, fatigue, nausea and drowsiness. The World Health Organization non-cancer 30 mins guideline value is $1000 \mu \mathrm{g} / \mathrm{m}^{3}$ based on odour annoyance. This study found toluene concentrations to be below the WHO standards, when participants were cooking with firewood.

Ethylbenzene and xylene were only emitted from Mushu and were not detected in the other firewood species. Exposure to ethlybenzene causes irritation of the eyes and throat, as well as liver disease. The odour threshold for ethylbenzene is $10,000 \mu \mathrm{g} / \mathrm{m}^{3}$ (ATSDR [11]). The WHO ambient air guidelines for xylene are 4800 for $24 \mathrm{hrs} \mu \mathrm{g} / \mathrm{m}^{3}$ and $870 \mu \mathrm{g} / \mathrm{m}^{3}$ as an annual value [9]. This study found the concentrations of ethylbenzene and xylene to be lower than those recommended by the World Health Organization. A pollutant at a concentration below its toxicological reference value is not considered to represent a health risk [11]. The comparison between the intake value (dose) and the dose-response value indicates the level of exposure to be below the toxicological reference value, which it is unlikely that even sensitive individuals will experience adverse health effects. 


\subsection{Exposure assessment}

The pollutants listed above can cause various health effects once exposure has occurred. Such health effects vary, depending on the length of time for which an individual has been exposed, and the concentrations s/he was subjected to. The respondents in Senwabarwana indicated that they cook once and/or twice a day (morning and/or evening). It is assumed that cooking takes approximately $1 \mathrm{~h}$ [44]. The kitchens are used mainly for cooking and body warming in winter. It was therefore necessary to assess the kitchen structures as they may influence exposure to firewood smoke during cooking. The structural design of kitchens in the study area is characterised by a limited number of windows, the size of which is usually small, thereby limiting the exchange of indoor air with outdoor air. It was observed that respondents opened windows and doors when cooking, to allow ventilation. However, pollutants cannot disperse properly due to poor kitchen structures putting residents at risk.

\subsubsection{Reported health effects}

Each of the products of firewood combustion has certain health effects on the human body. $46 \%$ of respondents self-reported headaches more frequently, followed by eye problems $(33 \%)$ - sore, red and teary eyes; the burning of biomass fuel produces smoke that irritates the eyes [11]. According to the International Agency for Research on Cancer (IARC) [9], VOCs are irritants to the eyes and respiratory tract, and are carcinogenic. Although relying on self-reported diseases may make the study unreliable, a case-control study of indoor cooking smoke exposure and cataract prevalence in Nepal and India found that the use of solid fuel in unfuelled indoor stoves is associated with an increased risk of eye problems with cataract development in women [11]. That study therefore supports the findings of the current study. In many households, everyday exposure to air pollution may contribute to an increasing prevalence of asthma and cancer [17]. In this study, $12 \%$ of respondents selfreported asthma, and 3\% self-reported cancer. Pneumonia was reported by only $1 \%$, whereas $9 \%$ reported heart problems and $4 \%$ reported incidents of strokes. Literature indicates that short-term exposure to high levels of the BTEX can cause symptoms like eye, nose and throat irritation, headaches, nausea and vomiting, dizziness, and the worsening of asthma symptoms. Scientific studies suggest that long-term, chronic exposure at high levels can cause an increased risk of liver damage, kidney damage, cancer, and central nervous system damage.

\subsubsection{Link between health effects and firewood species}

Fig. 3 presents the relationship between the firewood species used and health effects. This is a test of statistical significance to compare frequency of reported health effects by type of firewood species. It is observed that respondents who uses mushu more often reported highest health effects complains followed by those using mohwiliri, moretshe, motswiri and mokgwa respectively. Mushu was found to emit more volatile organic compounds compared to other firewood species. It is therefore not surprising that there are more complaints regarding health effects for mushu as compared to other firewood species.

\section{RISK ASSESSMENT}

This step combines the information from the two previous steps to provide an indication of the nature and expected frequency of adverse health effects in exposed populations. The fundamental assumption of the sampling strategy consists of the fact that measured concentrations represent maximum concentrations to which all individuals could be exposed 


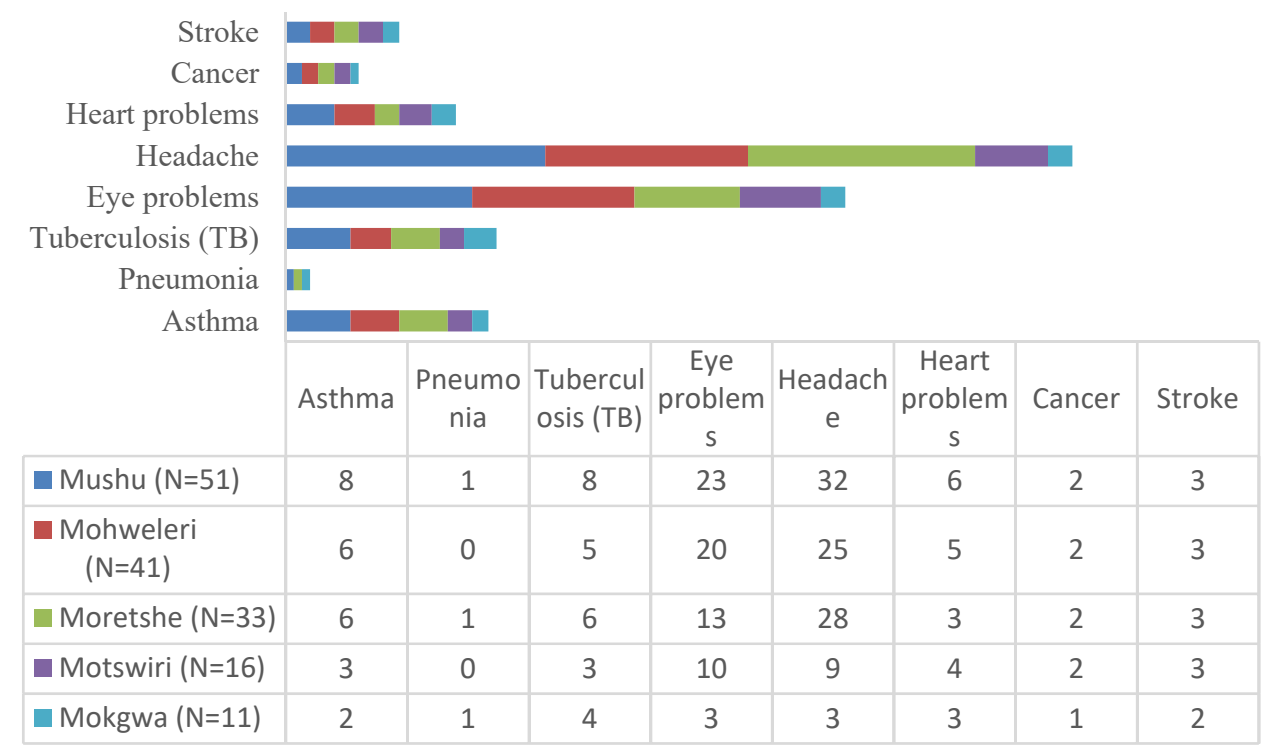

Figure 3: Link between health effects and firewood species.

in the kitchen [44]. If this assumption is true, then the risk of developing health effects due to the presence of the studied volatile organic compounds can be assessed as negligible. This holds for all Benzene, Toluene, Ethylbenzene and Xylene (BTEX) (concentrations remain below the risk levels).

Benzene poses a health risk in households where mushu and moretshe are used. There is, however, no health risk associated with the use of mokgwa, mohwiliri and motswiri. Similarly, toluene poses a health risk when mushu and moretshe are used, while there is no health risk associated with the use of mokgwa, mohweleri and motswiri. Ethylbenzene poses a health risk when mushu is used as firewood. Xylene has no health risk associated with the use of all five-tree species. Due to a limitation of this study monitoring volatile organic pollutants over a limited period, it was therefore not possible to estimate risks over longer periods of exposure (chronic health effects).

\section{CONCLUSION}

This study reviewed existing air pollution related risk assessment frameworks and research methods used. During such reviews, it emerged that despite the existing of numerous risk assessment frameworks and research methods followed, a huge gap was identified in both the frameworks and methods used. Consequently, an opportunity of developing an improved and Integrated Environmental Health Risk Assessment (IEHRA) framework was identified. Thus, one of the major contributions of the current study was to improve from known EHRA frameworks by developing the current IEHRA and ultimately conduct the study in Senwabarwana Villages using this improved framework.

It was found that firewood is the main source of energy. Volatile organic compounds emitted from the selected firewood were assessed. Mushu was found to emit the highest concentrations of BTEX. Ethylbenzene and xylene were not detected in Motswiri, Mohwiliri and Mokgwa, while benzene and toluene were detected below the detection limit of $1 \mu \mathrm{g} / \mathrm{m}^{3}$. 
The study found the VOC concentration to be below the WHO standards for those cooking with firewood. Each of the VOCs derived from firewood combustion has certain health effects on the human body. However, lower limits were detected in this study, suggesting that the community of Senwabarwana - which relies on firewood - is at lower risk of the ill effects associated with burning firewood. The risk assessment of health effects reported in Senwabarwana leads to the conclusion that reported health complaints are not due to the presence of the measured compounds. It is recommended that further studies be conducted on other pollutants emitted by these firewoods.

\section{REFERENCES}

[1] The Institute of Environmental Medicine, Environmental health risk assessment. https://ki.se/en/imm/environmental-health-risk-assessment. Accessed on: 5 Oct. 2018.

[2] National Health and Medical Research Council (NHMRC), Guidelines for Managing Risk in Recreational Water, Commonwealth of Australia: Canberra, 2008.

[3] Kapwata, T., Language, B., Piketh, S. \& Wright, C.Y., Variation of indoor particulate matter concentrations and association with indoor/outdoor temperature: A case study in rural Limpopo, South Africa. Atmosphere, 9(4), p. 124, 2018.

[4] Olave, R.J., Forbes, E.G.A., Johnson, C.R. \& Relf, J., Particulate and gaseous emissions from different wood fuels during combustion in a small-scale biomass heating system. Atmospheric Environment, 157, pp. 49-58, 2017.

[5] Mitchell, E.J.S., Lea-Langton, A.R., Jones, J.M., Williams, A., Layden, P. \& Johnson, R., The impact of fuel properties on the emissions from the combustion of biomass and other solid fuels in a fixed bed domestic stove. Fuel Processing Technology, 142, pp. 115-123, 2016.

[6] Parajuli, I., Lee, H. \& Shrestha, K.R., Indoor air quality and ventilation assessment of rural mountainous household of Nepal. International Journal of Sustainable Built Environment, 5(2), pp. 301-311, 2016.

[7] Jung, C.H., Matsuto, T. \& Tanaka, M., Behavior of metals in ash melting and gasification melting of municipal solid waste (MSW). Waste Management, 25(3), pp. 301-310, 2005.

[8] Joon, V., Kumar, K., Bhattacharya, M. \& Chandra, A., Non-invasive measurements of carbon monoxide in rural Indian women exposed to different cooking fuel smoke. Aerosol and Air Quality Research, 14(6), pp. 1789-1797, 2014.

[9] The National Academic Press, Toxicity testing. www.nap.edu/read/11523/chapter/3. Accessed on: 5 Oct. 2018.

[10] Kothari, C.R., Research Methodology, Methods and Techniques, 2nd ed., Prakashan: New Delhi, 1990.

[11] Agency for Toxic Substance and Disease Registry, The toxic guide. www.atsdr.cdc.gov/substances/toxsubstance.asp?toxid=14. Accessed on: 3 Oct. 2018.

[12] Creswell, J.W., Research Design: Qualitative, Quantitative and Mixed Methods Approaches, 4th ed., SAGE, 2014.

[13] Rumchev, K., Brown, H. \& Spickett, J., Volatile organic compounds: Do they present a risk to our health? Reviews on Environmental Health, 22(1), pp. 39-55, 2007.

[14] Gratt, L.B., Air Toxic Risk Assessment and Management: Public Health Risks for Normal Operations, Van Nostrand Reinhold, 1996.

[15] Langbein, J., Firewood, smoke and respiratory diseases in developing countries - the neglected role of outdoor cooking. PLOS ONE, 2017.

[16] Mouton, M., How to Succeed in your Masters and Doctoral Studies, Van Schaik Publishers: Pretoria, 2001. 
[17] Chakraborty, D., Mondal, N.K. \& Datta, J.D., Indoor pollution from solid biomass fuel and rural health damage: A micro-environmental study in rural area of Burdwan, West Bengal. Sustainable Built Environment, 3(2), pp. 262-271, 2014.

[18] Wright, C., Air pollution monitoring and evaluation framework for South Africa: prioritizing vulnerable communities. WIT Transactions on Biomedicine and Health, vol. 14. WIT Press: Southampton and Boston, pp. 55-64, 2009.

[19] Dai, H. et al., VOC characteristics and inhalation health risks in newly renovated residences in shanghai, China. Science of the Total Environment, 15(577), pp. 73-83, 2017.

[20] Azuma, K., Uchiyama, I., Uchiyama, S. \& Kunugita, N., Assessment of inhalation exposure to indoor air pollutants: Screening for health risks of multiple pollutants in Japanese dwellings. Environmental Research, 145, pp. 39-49, 2016.

[21] Nolte, C.G., Schauer, J.J., Cass, G.R. \& Simoneit, B.R.T., High polar organic compounds present in wood smoke and in the ambient atmosphere. Environmental Science Technology, 35, pp. 1912-1919, 2001.

[22] Williams, A., Jones, J.M., Ma, L. \& Pourkashanian, M., Pollutants from the combustion of solid biomass fuels. Progress in Energy and Combustion Science, 38, pp. 113-137, 2012.

[23] Plejdrup, M.S., Nielsen, O. \& Brandt, J., Spatial emission modelling for residential wood combustion in Denmark. Atmospheric Environment, 144, pp. 389-396, 2016.

[24] Ramos, M.A. \& De Albuquerque, U.P., The domestic use of firewood in rural communities of the Caatinga: How seasonality interferes with patterns of firewood collection. Biomass \& Bioenergy, 39, pp. 147-158, 2012.

[25] Tabuti, J.R.S., Dhillion, S.S. \& Lye, K.A., Firewood use in Bulamogi County, Uganda: Species selection, harvesting and consumption patterns. Biomass and Bioenergy, 25, pp. 581-596, 2003.

[26] Evtyugina, M. et al., Emission of volatile organic compounds from the residential combustion of Pyrenean oak and black poplar. International Journal of Environmental and Ecological Engineering, 7(6), pp. 289-293, 2013.

[27] Díez, H.E. \& Pérez, J.F., Physicochemical characterization of representative firewood species used for cooking in some Colombian regions. International Journal of Chemical Engineering, 2017(1), pp. 1-13, 2017.

[28] Venter, F. \& Venter, J., Making the Most of Indigenous Trees, Briza Publications: Pretoria, 1996.

[29] De Winter, B., De Winter, M. \& Killick, D.J.B., Sixty-Six Transvaal Trees. Botanical Research Institute: Pretoria, 1966.

[30] Machete, F., Environmental health risks associated with e-waste exposure in Badplaas, Carolina and Elukwatini landfills, Republic of South Africa. African Journal of Science, Technology, Innovation and Development, 9(6), pp. 679-684, 2017.

[31] Morakinyo, O.M., Adebowale, A.S., Mokgobu, M.I. \& Mukhola, M.S., Health risk of inhalation exposure to sub- $10 \mu \mathrm{m}$ particulate matter and gaseous pollutants in an urbanindustrial area in South Africa: An ecological study. Occupational and Environmental Medicine Research, 7(3), p. e013941, 2017.

[32] Oosthuizen, M.A., Wright, C.Y., Matooane, M. \& Phala, N., Human health risk assessment of airborne metals to a potentially exposed community: A screening exercise. The Clean Air Journal, 25(1), pp. 51-57, 2015.

[33] Thabethe, N.D.L., Engelbrecht, J.C., Wright, C.Y. \& Oosthuizen, M.A., Human health risks posed by exposure to $\mathrm{PM}_{10}$ for four life stages in low socio-economic community in South Africa. PanAfrican Medical Journal, 18(206), 2014. 
[34] Habeebullah, T., Risk assessment of exposure to volatile organic compounds in the holy city of Makkah. Environment Impact, 162, pp. 625-635, 2012.

[35] Muller, E., Diab, R.D., Binedell, M. \& Hounsome, R., Health risk assessment of kerosene usage in an informal settlement in Durban, South Africa. Atmospheric Environment, 37, pp. 2015-2022, 2003.

[36] Cattaneo, A. et al., Comparison between personal and individual exposure to urban air pollutants. Aerosol Science and Technology, 44(5), pp. 370-379, 2010.

[37] Department of Health, Guideline for the Management of Indoor Air Quality: A Guide for Environmental Health Practitioners in South Africa, Pretoria, 2018.

[38] Scientific Kit Corporation, Application guide (Sampling train-air sample bags). www.skcltd.com. Accessed on: 14 Feb. 2018.

[39] Hopkins, D. \& Williams, D., Guidance on human health risk assessment for environmental impact assessment in Alberta. Edmonton.

https://open.alberta.ca/publications/guidance-on-human-health-risk-assessment-forenvironmental-impact-assessment-in-alberta. Accessed on: 8 Oct. 2018.

[40] Cheng, Z., Li, B., Yu, W., Wang, H., Zhang, T. \& Bu, Z., Risk assessment of inhalation exposure to VOCs in dwellings in Chongqing, China. Healthy Buildings 2017 Europe, 2017.

[41] Inkoom, D.K.B. \& Crentsil, A.O., Estimation of indoor air pollution and health impacts due to biomass burning in rural northern Ghana, in case studies for developing globally responsible engineers. Global Dimension in Engineering Education, ed. GDEE, Barcelona. http://gdee.eu/index.php/resources.html. Accessed on: 5 Oct. 2018.

[42] Woolfenden, E., Sorbent-based sampling methods for volatile and semi-volatile organic compounds in air - Part 1: Sorbent-based air monitoring options. Journal of Chromatography A, 1217(16), pp. 2674-2684, 2010.

[43] Gawryś, M., Fastyn, P., Gawłowski, J., Gierczak, T. \& Niedzielski, J., Prevention of water vapour adsorption by carbon molecular sieves in sampling humid gases. Journal of Chromatography A, 933(1-2), pp. 107-116, 2001.

[44] United States Environmental Protection Agency (USEPA), Framework for human health risk assessment to inform decision making. www.epa.gov/sites/production/ files/2014-12/.../hhra-framework-final-2014.pdf. Accessed on: 26 Sept. 2018. 